\title{
Zell - Desenvolvimento do CDA para a disciplina de biologia celular
}

\author{
Vitor C. S. Valadares ${ }^{1}$, Guilherme T. Schneider ${ }^{1}$, André B. Trombetta ${ }^{1}$, João B. \\ Mossmann', Marta R. Bez ${ }^{1}$, Richard N. Silva ${ }^{1}$, Thiago G. Mendes ${ }^{1}$ \\ ${ }^{1}$ LOA - Laboratório de Objetos de Aprendizagem - Universidade Feevale \\ ERS 239, 2755 - 93.600-000 - Novo Hamburgo - RS - Brasil \\ \{vitorvaladaresbr, gtschneider, trombetta, mossmann, martabez, \\ richard.n.silva\}@gmail.com, thiagogmefeevale.br
}

\begin{abstract}
The present work aims to show the development process of the Digital Learning Construct Zell. Authors who support the use of games on education and the methodology applied will be introduce. The construct aims to reinforce the theme of cellular transportation. The project was created by the Laboratory of Learning Objects of University Feevale, in partnership with the Health Sciences Institute of the same institution. The CDA was applied during the first semester of 2015, on four classes of cellular biology, which answered a questionnaire applied to the end of the sessions, in order to validate the use of CDA as a discipline support tool.
\end{abstract}

Resumo. O presente artigo tem o objetivo de apresentar o processo de desenvolvimento do Construto Digital de Aprendizagem (CDA) Zell. Serão introduzidos autores que reforçam o uso de jogo na educação e a metodologia aplicada. O construto é voltado para o reforço do conteúdo de transporte celular. O projeto foi produzido pelo laboratório de objetos de aprendizagem da Universidade Feevale em parceria com o Instituto de Ciências da Saúde da própria instituição. O CDA foi aplicado no primeiro semestre de $2015 \mathrm{em}$ quatro turmas da disciplina de biologia célula, que responderam ao questionário aplicado ao termino das sessões, na qual se buscou validar o uso do CDA como apoio à disciplina.

\section{Introdução}

O desenvolvimento de um Construto Digital de Aprendizagem (CDA) para a disciplina de biologia celular, da Universidade Feevale, foi iniciado a partir da união de esforços entre o Instituto de Ciências da Saúde (ICS) e o Instituto de Ciências Sociais Aplicadas (ICSA) através do Laboratório de Objetos de aprendizagem (LOA). As professoras responsáveis pela disciplina apresentaram uma aula expositiva para os integrantes do LOA, na qual foram introduzidos os conteúdos didáticos referentes a biologia celular, utilizando, sempre que possível, a mesma metodologia empregada em sala de aula. A partir destas aulas, as professoras e a equipe passaram a identificar possíveis recortes do conteúdo que tinham potencial de serem transportados para um CDA. Neste momento do projeto, as professoras tinham em mente dois conteúdos distintos: transporte celular e proteínas. 


\section{CBIE-LACLO 2015}

Anais dos Workshops do IV Congresso Brasileiro de Informática na Educação (CBIE 2015)

A partir dessa apresentação, iniciou-se uma discussão com a equipe, que entendeu que o conteúdo de proteínas exigia um grau maior de complexidade na produção. Tal questão poderia tornar o CDA mais estático e menos lúdico, fugindo portanto de algumas das diretrizes de trabalho desenvolvidas no LOA. O método de criação de CDAs aponta para a construção de construtos que proporcionem mais experimentação e ludicidade (Bez et al, 2013). Desta forma, optou-se, em negociação com conteudistas e equipe de desenvolvimento, pelo uso do conteúdo de transporte celular.

Após essa etapa, os integrantes do LOA demonstraram os CDAs já produzidos, apresentando quais conteúdos já tinham sido trabalhados em outros CDAs, como tinham sido convertidos em sistemas de jogo e também como ficou a interação do aluno com cada conteúdo apresentado. A intenção desta etapa é que os conteudistas possam se apropriar da linguagem dos CDAs, as formas diferentes de aplicá-los nas dinâmicas das disciplinas, os diferentes objetivos que têm entre si e também os recursos de tempo e pessoas disponíveis para que o CDA seja desenvolvido.

Na sequência, foi iniciado um brainstorm, para determinar qual seria a narrativa utilizada e o tipo de mecânica de jogo que poderia contemplar o conteúdo que era pensado para o CDA. Foram feitas reuniões entre as conteudistas e os integrantes do LOA, para apresentar ideias e tirar dúvidas de conteúdo de biologia celular. Durante tais reuniões, houveram alguns embates entre as linhas de pensamento das equipes que divergiam sobre a carga e a forma de apresentação de conteúdos. Um dos embates recorrentes na produção de quase todos os CDAs produzidos pelo LOA - é uma propensão dos professores conteudistas à colocação de uma quantidade excessiva de material textual (pdfs, textos longos, etc.) dentro do sistema. Essa propensão parece ser o resultado de uma preocupação em se certificar de que todo o conteúdo estará disponível ao aluno da mesma forma que em um livro didático, desconsiderando que a proposta do CDA não é a substituição do professor ou de outros materiais mas sim a de ofertar aos alunos uma experiência diferente ao lidar com o conteúdo, com uma utilização mais rica em metáforas e uma experiência mais lúdica.

Após as discussões entre todos, as ideias foram ganhando forma e contexto. Por fim, a equipe do LOA decidiu por uma narrativa de ficção científica e o conteúdo seria abordado na forma de transporte celular. As professoras conteudistas concordaram com a narrativa e sugeriram que precisavam de mais entrega de conteúdo, o que acarretou na criação de um $L O G$ no jogo, onde ficam armazenados todos os conteúdos. Nessa negociação da escolha da narrativa a preocupação por uma verossimilhança na apresentação do conteúdo tende a fazer com que os conteudistas olhem com alguma desconfiança para o uso de metáforas, uma das maiores dificuldades para muitos dos professores conteudistas com os quais o LOA têm trabalhado nos últimos anos.

Cada etapa do processo de produção foi aprovada e validada com as professoras. Porém, a quantidade de conteúdo e forma como era pensado o conteúdo era diferente para a equipe do LOA e das professoras. A tensão para determinar o ideal de conteúdo foi o desafio que será demonstrado no item abaixo. 


\section{O Desafio da Adaptação de Conteúdos}

O principal desafio, talvez o maior para a produção de jogos educativos, tem sido a questão de como adaptar para um jogo o conteúdo que o professor imagina para seus alunos. O que ocorre em muitas experiências, é que o professor constrói o que deseja passar com o conteúdo, colocando esse material de forma textual, não levando em consideração as características lúdicas que um jogo possui. Em contrapartida o desenvolvedor do jogo sempre vai propor que o conteúdo fique em segundo plano.

Conforme BRANCO et. al. (2013), os Construtos Digitais de Aprendizagem são jogos/sistemas de aprendizagem digitais produzidos a partir de uma lógica multidisciplinar. São resultado do diálogo e embate entre as áreas da educação, comunicação, design e informática, sem que uma se sobreponha a outra. A partir da experiência do grupo de pesquisadores e desenvolvedores do LOA no desenvolvimento de CDAs, o que se percebeu não é um problema relacionado a visões diferentes sobre o uso dos jogos na educação. Nesse ponto, professores e desenvolvedores concordam: os jogos são ferramentas promissoras do ponto de vista educacional, especialmente por sua alegada capacidade de sedução junto aos nativos digitais.

$\mathrm{Na}$ experiência do desenvolvimento do jogo Zell, o grupo percebeu que a troca dos conhecimentos, tanto por parte do conteúdo e também pela mídia jogo, é fundamental para que se encontre uma maneira de adequar o aspecto narrativo que a equipe do LOA tinha a intensão de adotar. Ao mesmo tempo, as professoras conteudistas, apresentavam alternativas de abordagem que contribuíram para o aspecto narrativo e de conteúdo que foi construído no jogo Zell. Para PRENSKY (2001) aprendizagem baseada em jogos digitais é resolver e inventar formas de incluir reflexão e pensamento crítico com aprendizagem e ainda fazer um jogo divertido (2001, p. 51).

Johnson (2005) defende que, não importa o que o jogador pensa enquanto joga. O que importa é a maneira como o jogador está pensando. Essa afirmação é reforçada por Dewey (1997) ao defender que a maior de todas as falácias pedagógicas talvez seja a noção de que uma pessoa aprende apenas aquela determinada coisa que está estudando. Nesse aspecto, destaca a aprendizagem colateral no caminho para formar atitudes de construção duradouras, sendo essas, com frequência, mais importantes do que as aulas de gramática ou as aulas de geografia e história que são aprendidas.

\section{Desenvolvimento}

O processo de desenvolvimento do projeto Zell se deu em três momentos distintos que se estenderam por aproximadamente três semestres. A primeira etapa, da definição do jogo e apropriação de conteúdo, na qual a equipe do LOA, juntamente com as professoras conteudistas, tomou conhecimento do assunto a ser abordado, definiu o escopo para o jogo e quais os resultados esperados a partir da aplicação do mesmo com o público alvo.

Em seguida, ocorreu o período de produção do Construto Digital de Aprendizagem (CDA), englobando aqui os meses dedicados à criação dos protótipos, da concepção de assets audiovisuais, a implementação dos sistemas de jogo, o level design em função do conteúdo e do balanceamento do gameplay. 
Por fim, houve a etapa de aplicação e análise dos resultados com quatro turmas da disciplina de Biologia Celular. Cada uma das etapas será discutida nos parágrafos a seguir. Durante o desenvolvimento buscou-se seguir o método de produção de CDA proposto por Bez et al (2012) que sugere uma estrutura não hierárquica de desenvolvimento que une esforços de quatro grandes áreas: educação, comunicação, design e informática.

\subsection{Definição do jogo e apropriação de conteúdo}

Visando auxiliar na elaboração do escopo e do recorte do conteúdo abordado pelo jogo, a equipe do Laboratório de Objetos de Aprendizagem (LOA) assistiu breves apresentações em formato de aula sobre os temas propostos para entrarem no game. Tais palestras foram lecionadas pelas próprias professoras conteudistas envolvidas no projeto. A partir de tais exposições, o grupo pode se apropriar melhor da temática e com isso ser capaz de chegar ao consenso sobre o assunto geral do game: o transporte celular.

As professoras concluíram que o CDA seria melhor utilizado se aplicado após a introdução do conteúdo, sendo assim, definiu-se que o resultado esperado seria o de retenção do tema abordado. Também combinaram que o game seria utilizado em sala de aula, mas que o mesmo estaria disponível para uso do aluno fora do ambiente acadêmico. O projeto seria desenvolvido para funcionar em browser, seguindo o padrão de desenvolvimento de CDAs do LOA.

Após chegarem no consenso sobre o escopo e a abordagem, pode-se definir o high-concept do jogo: Um CDA voltado para alunos das disciplinas de biologia celular, tendo como recorte o conteúdo de Transporte Celular. Nele, o estudante vai controlar uma nave que tem o papel de sintetizar, coletar e entregar nutrientes com o objetivo de manter as células vivas.

\subsection{Prototipagem e Produção}

Foram definidos, então, os protótipos e criados os concepts do CDA, numa fase de préprodução. Foi estipulado que o jogo entregaria o conteúdo didático tanto de forma explicita, através de mensagens e painéis que elucidariam e explicariam conceitos de biologia relacionados ao conteúdo, como também de forma implícita, através de artifícios visuais e das mecânicas de jogo, tal qual a que exige que o jogador sintetize uma proteína para extrair o nutriente necessário à célula, por exemplo. Por fim, para facilitar a abordagem de conteúdo, a equipe deixou a cargo das professoras conteudistas dividir o assunto em pequenas partes que seriam tratadas dentro de missões distintas.

Ao término das etapas de definições, a equipe pode iniciar a produção, que representa o segundo grande momento do desenvolvimento. Foi criado o primeiro protótipo blocado do jogo, no qual foi implementado e avaliado inicialmente apenas as mecânicas de jogabilidade, não necessariamente a entrega do conteúdo, como apresentado na Figura 1. 


\section{CBIE-LACLO 2015}

Anais dos Workshops do IV Congresso Brasileiro de Informática na Educação (CBIE 2015)

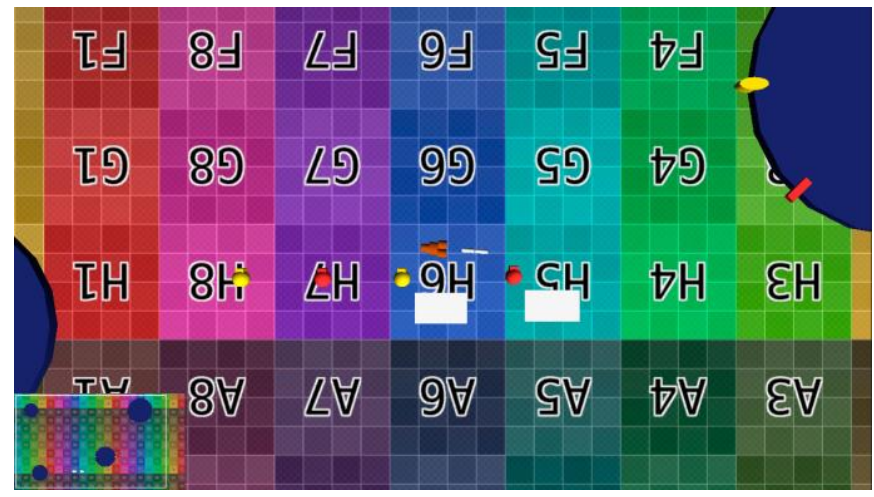

Figura 1 - Protótipo blocado do CDA Zell

Buscando-se reduzir o atraso no desenvolvimento, a equipe decidiu realizar os testes do protótipo já com a adição de parte dos modelos visuais, o que poderia ser considerado uma versão alpha, apresentado na Figura 2. Conforme ficou definido anteriormente, o visual teria como tema o sci-fi, aplicado tanto ao conceito da nave como da interface, que buscou remeter à uma cabine de comando, deixando claro de que o CDA usa um conceito metafórico e não uma simulação.

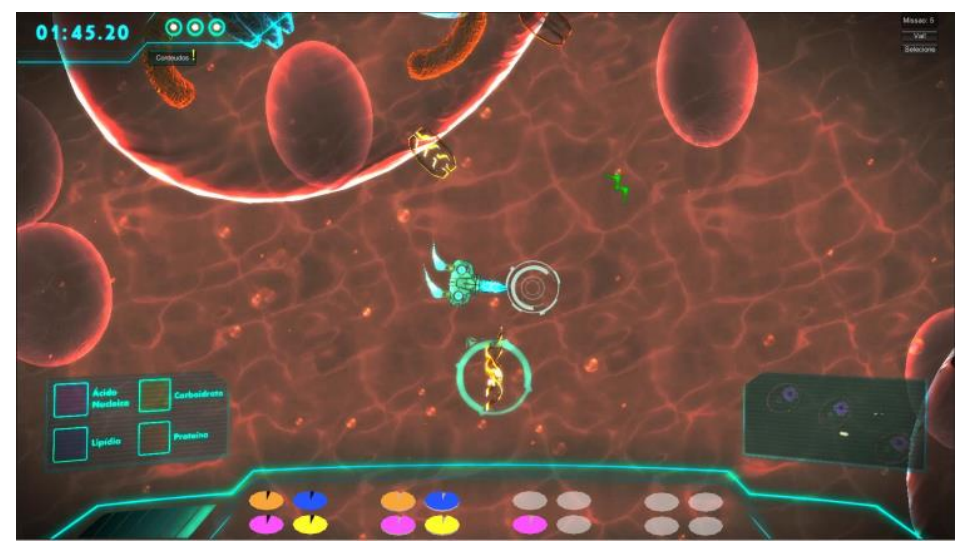

Figura 2 - Versão alpha do CDA Zell

Uma avaliação desta versão foi realizada com um pequeno grupo de ex-alunas da disciplina de Biologia Celular. A avaliação foi realizada no laboratório do LOA, utilizando-se de um método semelhante ao Think-Aloud (Erikson e Simon, 1993), na qual se observou o uso do construto pelo grupo de avaliação e realizaram-se apontamentos a partir de tais observações. Não foram realizadas capturas de áudio e vídeo no momento da avaliação. Dentre os principais pontos relatados, destaca-se a dificuldade no controle da nave, devido à grande quantidade de comandos necessários para realizar a ação, o que aparentou ser complexo para quem não possui o costume de jogar, assim como o descontentamento com a extensão do tutorial. Também foi percebida uma falta de interação com a aba de conteúdo explicito e o não entendimento do significado de parte da interface, como o indicador de nitro, os gráficos de nutrição e a leitura do mapa.

Tendo sido realizada a coleta de dados com esta aplicação prévia, a equipe passou a aplicar correções e melhorias ao projeto com o intuito de resolver os problemas 


\section{CBIE-LACLO 2015}

Anais dos Workshops do IV Congresso Brasileiro de Informática na Educação (CBIE 2015)

apontados e aproximar o CDA do que viria a ser a versão final (Figura 3). A partir deste momento, as reuniões com as professoras conteudistas passaram a se tornar mensais ao invés de semanais ou quinzenais, como vinham ocorrendo. Os demais membros da equipe do LOA continuaram a se encontrar e discutir o game semanalmente.

Dentre as melhorias realizadas destaca-se a busca por uma interface mais direta na entrega de informações. Os indicadores de necessidades das células passaram a contar com um percentual que explicita o quão nutrida cada célula está para cada tipo diferente de nutriente, indicado pelas cores que são reutilizadas em demais locais da interface e do jogo. Cada célula também ganhou um número, que pode ser lido através do mapa do canto direito assim como no painel de nutrição. Ainda sobre o mapa, passou-se a exibir de forma mais destacada a posição de cada item relevante ao jogador. O combustível do nitro também ganhou uma legenda para tornar o indicador mais evidente. Foi acrescentado um espaço que serve de $\log$ ao aluno, utilizado para mostrar informações que possam ser importantes para o sucesso de cada missão.

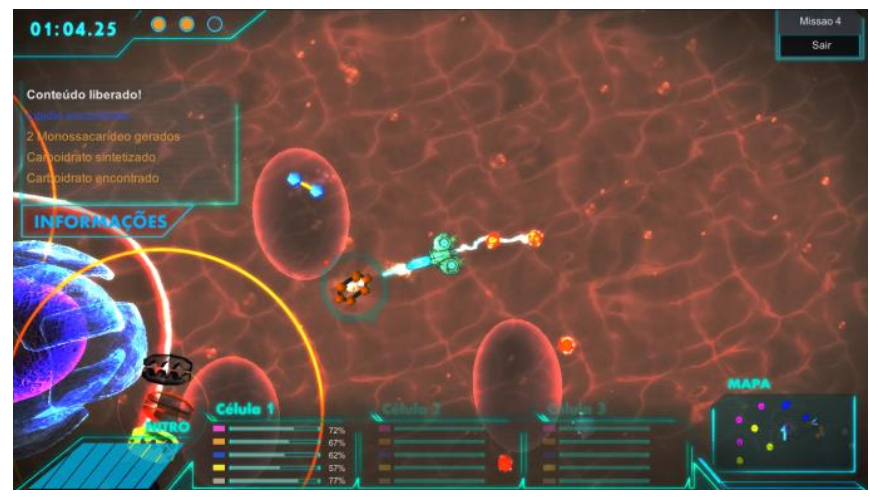

Figura 3 - Versão final do CDA Zell

Após as correções mencionadas, o CDA foi aplicado em turmas de graduação de diferentes cursos da Universidade Feevale que incluem a disciplina de Biologia Celular na sua grade curricular. $O$ jogo pode ser acessado através do link http://games.feevale.br/loa/zell. $\mathrm{O}$ construto possui um sistema de acesso que comunica-se com o sistema administrativo da Universidade Feevale para validar o código e a senha do aluno. Existe, também, uma versão para o público em geral cujo acesso se dá pelo usuário "visitante" e a senha "visitante". Além disso, um vídeo demonstrativo foi disponibilizado através do endereço http://youtu.be/YLH3R5Xm7IY.

\section{Aplicações e Resultados}

No primeiro semestre de 2015 o CDA foi aplicado a 4 turmas da disciplina de Biologia Celular, o que englobou a participação de alunos dos cursos de Biologia, Biomedicina, Ciências Biológicas, Farmácia, Fisioterapia, Nutrição e Quiropraxia. O total de alunos atendidos foi 159, sendo 126 do sexo feminino e 33 do sexo masculino. Foi questionado aos respondentes que indicassem quantas vezes por semana jogam no computador. Destes, 40 indicaram não jogar nunca, 1 que jogava uma vez por mês, 12 que jogavam 


\section{CBIE-LACLO 2015}

Anais dos Workshops do IV Congresso Brasileiro de Informática na Educação (CBIE 2015)

até 3 vezes por semana, um que jogava de 4 a 8 vezes e 6 responderam jogar mais de 8 vezes por semana.

O que se percebe é um grupo onde a maioria não costuma usar jogos digitais, fato que chama a atenção, pois é um grupo bem jovem e normalmente estes costumam jogar. Acredita-se que isso se deve ao grande número de participantes do sexo feminino que responderam aos questionários.

\section{Considerações Finais}

Ao analisar as respostas recebidas dos questionamentos sobre a metodologia e a aprendizagem com o uso do CDA Zell pode ser percebida uma alta aceitação do mesmo pelo corpo discente. Em todos os quesitos avaliados, a aceitação ficou entre $90 \%$ e $100 \%$, o que demonstra que o uso do CDA pode ser efetivo e que sua proposta pode auxiliar no processo de ensino e aprendizagem de biologia celular, envolvendo o tema transporte celular.

Percebeu-se que os alunos acreditam que o CDA sozinho não é suficiente para o pleno aprendizado do conteúdo. Tal resposta já era esperada, uma vez que desde o princípio do seu desenvolvimento este foi pensado como um recurso de apoio a ser utilizado após a apresentação do conteúdo teórico aos alunos.

Em contrapartida, a abordagem do conteúdo de forma menos textual agradou e atraiu os alunos da disciplina de biologia celular. Da mesma forma, no que diz respeito ao visual do jogo e sons, a receptividade dos alunos no teste foi excelente e as cores em muitas partes do jogo, segue o mesmo padrão utilizado nos materiais didáticos.

Após a validação com as turmas, novas melhorias foram realizadas ao construto, visando melhorar e facilitar a compreensão do tutorial que ensina a jogar. $O$ jogo atualmente consta no plano de ensino da disciplina de Biologia Celular e deverá ser utilizado nos próximos semestres.

\section{Bibliografia}

Bez, M. R., Mossmann, J. B., Mendes, T. G., Branco, M. (2012) "Projeto para Desenvolvimento de Objetos de Aprendizagem no Formato de Jogos Sérios". In: Congreso Internacional de Ambientes Virtuales de Aprendizaje Adaptativos y Accesibles, 4., 2012, Cartagena. Anais do IV Congreso Internacional de Ambientes Virtuales de Aprendizaje Adaptativos y Accesibles, Cartagena: Cava, 2012, v.1, p. 110 .

Branco, M., Bez, M. R., Mossmann, J. B., Mendes, T. G. (2013) "Dimensões dos Jogos de Ensino". In: ICECE'2013 - Congresso Internacional em Educação em Engenharia e Computação, 2013, Luanda. Anais do ICECE'2013 - Congresso Internacional em Educação em Engenharia e Computação. São Paulo: COPEC, 2013. v. 1. p. 277-281.

Ericsson, K., Simon, H. (1993) "Protocol Analysis: Verbal Reports as Data". Cambridge, MA: The MIT Press.

McGonigal, Jane. (2011). "Reality is Broken”. New York: Penguin Press.

Prensky, M. (2001). “Digital Game-Based Learning”. St. Paul: Paragon House. 